\title{
Utilisation of hydrogeothermal energy by use of heat pumps in Serbia - current state and perspectives
}

\author{
Dejan Milenic $^{1 *}$, Ana Vranjes ${ }^{1}$ \\ ${ }^{1}$ Univesity of Belgrade, Faculty of Mining and Geology, Department for Hydrogeology, Belgrade, Serbia \\ "Tel/fax: +381 113346 000, , E-mail: dmilenic@yahoo.ie
}

\begin{abstract}
The development strategy of the energy sector in Serbia anticipates the intensive utilisation of renewable hydrogeothermal energy sources by using energy efficient technologies. The main aim of the paper is to perceive, for the first time, quantities and possibilities of the utilisation of available hydrogeothermal energy accumulated in groundwater with the temperature up to $30^{\circ} \mathrm{C}$ in the concept of the substitution of fossil fuels by renewable en ergy sources in the Republic of Serbia. The available quantities of groundwater have been observed by regions whose borders correspond with hydrogeological characteristics of the terrain and conditions of groundwater formation. The territory of the Republic of Serbia is divided into eastern part, to which there belong estimated quantities of about $7400 \mathrm{l} \cdot \mathrm{s}^{-1}$, namely the available heat power amounts about $200 \mathrm{MW}$, central and western parts of the territory (to which the capital city Belgrade also belongs) have about $14900 \mathrm{l} \cdot \mathrm{s}^{-1}$, which is adequate to about $400 \mathrm{MW}$ of heat power, and northern part of the territory with available $6600 \mathrm{l} \cdot \mathrm{s}^{-1}$, namely about $180 \mathrm{MW}$ of heat power. If we take into account the territory of the whole Republic, the available resources of subgeothermal energy amount about $28 \mathrm{~m}^{3} \cdot \mathrm{s}^{-1}$, namely over $770 \mathrm{MW}$ of heat power.
\end{abstract}

Keywords: Hydrogeothermal energy, Subgeothermal energy, Groundwaters, Serbia

\section{Introduction}

According to development plans in the field of energetics and energy efficiency of the Republic of Serbia, hydrogeothermal resources belong to renewable energy sources whose application and utilisation, namely the verification of reserves is in its initial phase. The potential and reserves are not examined and explorations of this kind of renewable energy have become significant lately. The strategy of energy development in Serbia anticipates the intensive utilisation of renewable hydrogeothermal energy sources, especially low temperature groundwater via the energy efficient technologies by using heat pumps.

The main aim of the paper is to perceive, for the first time, quantities and possibilities of the utilisation of available hydrogeothermal energy accumulated in groundwater with the temperature up to $30{ }^{\circ} \mathrm{C}$ (subhydrogeothermal energy) in the concept of the substitution of fossil fuels by renewable energy sources in the Republic of Serbia. In the past three years subhydrogeothermal energy resources have been classified in Serbia for the first time (Milenic et.al. 2010, V ranjes 2008), as well as the valorisation of available resources of subhydrogeothermal groundwaters (Stevanovic et al.2010). Hydrogeothermal resources of low enthalpy (fluid temperature to $100^{\circ} \mathrm{C}$ ) have been classified as the sub(hidro)geothermal energy (fluid temperature to $30^{\circ} \mathrm{C}$ ) and hydrogeothermal energy in the narrow sense (fluid temperature from $30^{\circ} \mathrm{C}$ to $100^{\circ} \mathrm{C}$ ). Further in the text, for the sake of simplification, the notion: "sub(hydro)geothermal energy" will be used as subgeothermal energy.

On the basis of the mentioned explorations, the definition of subgeothermal energy sources has been deduced: "subgeothermal energy sources are a kind of hydrogeothermal energy of low enthalpy accumulated in groundwaters of the temperature scope to $30^{\circ} \mathrm{C}$, and whose exploitation and utilisation are conditioned by the application of geothermal heat pumps".

Consequently, groundwaters with the temperature of $30^{\circ} \mathrm{C}$ are significant subgeothermal resources, especially in alluvial plains and Neogene basins in the Republic of Serbia. On the basis of classifications stated in this way, the scientific-research project initiated in the year 
2008 (Stevanovic et al.2010), evaluated the availability of groundwater resources which can be used as sources of subgeothermal energy (SGTE) as a kind of hydrogeothermal energy of low enthalpy.The obtained results point out the enormous potential of groundwater in the concept of utilisation as a renewable energy source. However, a small number of subgeothermal systems worked out so far points out the necessity of wider engagement of both the state and independent experts in the sense of awareness are using of the significance of this kind of renewable energy.

The significance of explorations and the utilisation of subgeothermal energy can be seen in the following: groundwater is "easy" for taping and the energy resource is inexpensive for development and exploitation, a l ocally available resource is used via relatively simple technology, the conservation of fossil fuels (oil, natural gas) by the renewable energy source, the increase of self-sufficiency and the sustainability of energy consumption, the increase of environmental quality through the decrease, namely the reduction of the emission of hazardous gases, such as $\mathrm{CO}_{2}$ ( up to $75 \%$ in relation to a conventional heating procedure) the improvement of image in public, financial savings due to the reduced purchase of fossil fuels, and the introduction of the principle of "sustainable development".

\section{Applied methodology}

Hydrogeological and hydrogeothermal explorations in this field are of a highly multidisciplinary character and imply the engagement of researchers from the field of hydrogeology (geothermal resource provision), mechanical engineering (thermo engineering part, the utilization of SGTE), and architecture (the increase of energy efficiency and the correct utilization of SGTE in building).

Hydrogeological explorations imply the evaluation of resource availability, as to:

1. Quantity defining:

i) hydrogeological regionalisation of the territory of Serbia

ii) defining of aquifer types within each hydrogeological region

iii) carrying out of pumping tests at the existing wells within the particular aquifer type

iv) yield measurements at springs within the particular aquifer type

v) collecting and synthesis of results of past explorations in the field of hydrogeology

2. Defining of aquifer hydrodynamic characteristics:

i) calculation of environmental basic parameters

ii) workingout of aquifer hydrodynamic model

3. Defining of physic-chemical characteristics:

iii) determining of ground water temperature regime

iv) determining of qualitative regime

v) basic chemical composition of ground water

vi) water aggressiveness (corrosiveness /inscrutability)

After available quantities of subgeothermal energy had been defined, the data obtained in additional explorations were used in discussions, first of all:

Thermodynamic and energy explorations, i.e. calculation of required energy quantity for the heating building / buildings (building energy consume) and techno-economical analyses, i.e. the economical analysis of the investment cost-efficiency in the utilisation of renewable 
energy resources comparative analysis of expenses for various fuels and the period of investment cost-efficiency.

The aim of the work methodology set in this way was, first of all, hydrogeological. The paper did not deal, in details, with the efficiency of the utilisation of heat pumps, the analysis of COP, etc. As regards that the utilisation of heat pumps in Serbia is in its initial state, it is not possible to give any detailed analyses of the mentioned parameters of the heat pump work.

\section{Survey of subgeothermal potential in Serbia}

The Republic of Serbia is pronouncedly rich in hydrogethermal resources (Fig.1a). The waters of Vranjska Banja Spa $\left(96^{\circ} \mathrm{C}\right)$, Josanicka Banja Spa $\left(78^{\circ} \mathrm{C}\right)$ and some others have the highest temperature. Groundwater with the temperature over $30^{\circ} \mathrm{C}$ is relatively well utilised. Unlike them, groundwater with temperatures up to $30^{\circ} \mathrm{C}$ (subgeothermal energy) has not been the subject of explorations from other points of view, except for the needs of water supply. Development of heat pump systems, their growing commercialisation and application in the world, have resulted in increased possibilities of multipurpose utilisation of this water.The availability of subgeothermal groundwater resources is mainly related to depth up to $200 \mathrm{~m}$ from the surface of the terrain and, on the territory of Serbia it is not evenly spaced. The largest quantities of this kind of energy are related to alluvions of big rivers, especially in towns they run through. Due to the heat island effect, temperatures of groundwater in towns are higher in relation to rural environment, thus the energy potential is higher. On the basis of carried out preliminary explorations of the assessment of groundwater resources with the temperature up to $30^{\circ} \mathrm{C}$, the territory of the Republic of Serbia is a highly prospective one, from the point of view of the utilisation of subgeothermal energy. The available quantities of groundwater have been considered by regions, whose boundaries are adequate to hydrogeological characteristics of the terrain and conditions of groundwater formation. Available heat power of low enthalpy hydrogeothermal energy was calculated from the following equation (Eq.1):

$$
E=C_{p} \cdot Q \cdot \Delta T
$$

where:

E - available heat power (KW, MW)

$\mathrm{C}_{\mathrm{P}} \quad$ - the specific heat of water (constant, $4.2 \mathrm{KJ} \cdot \mathrm{kg}^{-1} \cdot{ }^{\circ} \mathrm{C}^{-1}$ )

Q - yield of the wells $\left(\mathrm{kg} \cdot \mathrm{s}^{-1}\right.$, the same as $\left.l \cdot \mathrm{s}^{-1}\right)$

$\Delta \mathrm{T} \quad$ - temperature reduction which can be realised in the heat pump $\left({ }^{\circ} \mathrm{C}\right)$

The areas of big towns in Serbia have special potential, which due to the hot island effect have the most favourable subgeothermal characteristics with raised temperatures of groundwater even to $5^{\circ} \mathrm{C}$ in relation to the remaining territory. The "heat island" effect is a consequence of urbanisation, leading to micro climatic changes expressed as air temperature raising. This temperature increase can reach $5^{\circ} \mathrm{C}$, in relation to inurbane suburbs. Being highly urbanised the City of Belgrade (the city core covers an area of over $10 \mathrm{~km}^{2}$, with more than 1,500.000 inhabitants) has all predispositions for heat island effect occurrence. The geological characteristics of the Belgrade area conditioned the existence of significant quantities of ground waters where heat effect is induced as temperature anomaly. 


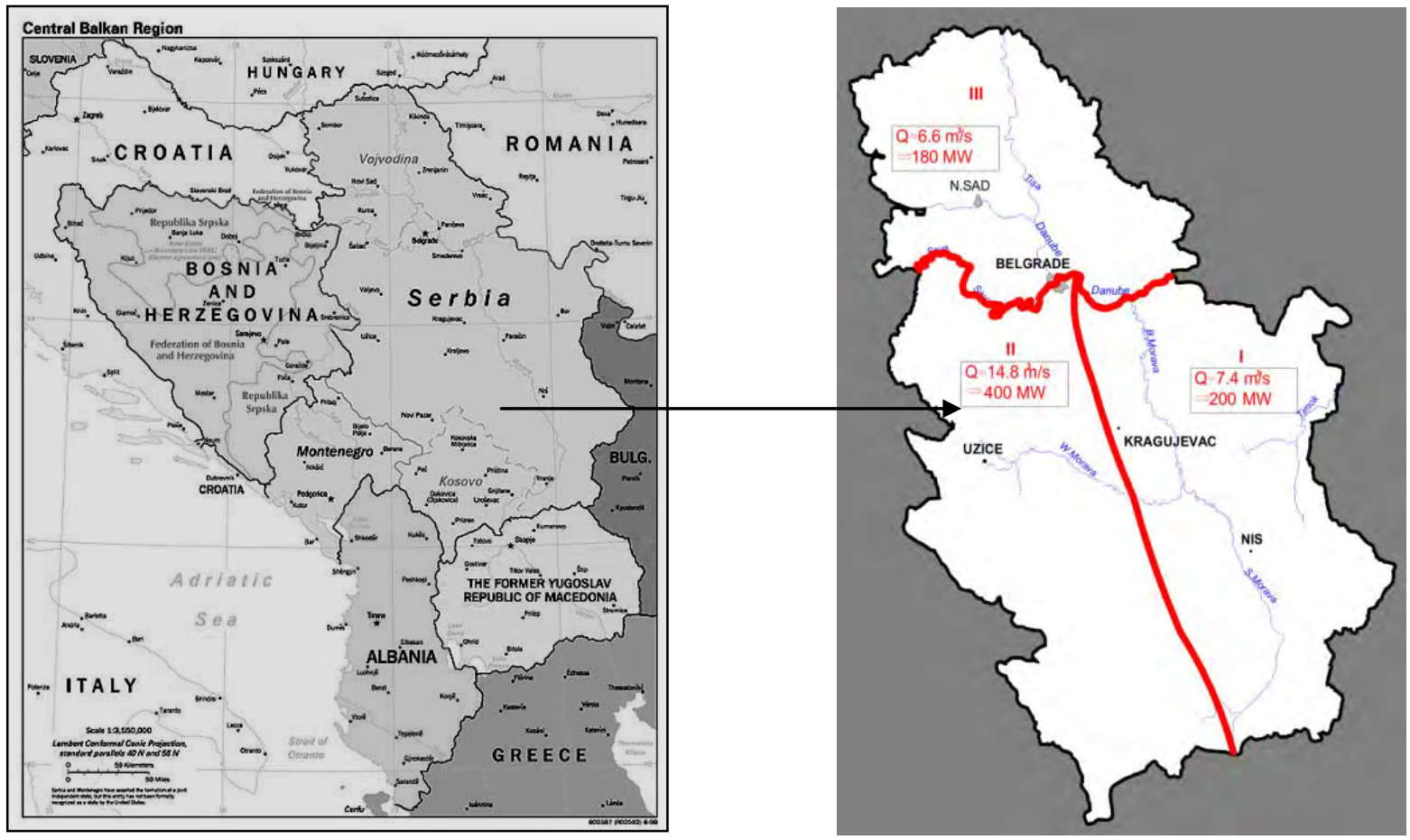

Fig. 1. a)Geographical position of the study area, b)Partition of the investigation area

The available energetic potential of ground water on carried out test exploited wells in New Belgrade goes over $0.5 \mathrm{MW}$ for an individual well. This record was obtained by using minimal well yield of about $1,000-1,500 \mathrm{~m}^{3} /$ daily and minimal temperature of ground water of 13 to $15^{\circ} \mathrm{C}$. Hydroisotherms point out clearly that the groundwater temperature in lesser urbanised areas amounts $13-14^{\circ} \mathrm{C}$. Moving to central and highly urbanised parts of New Belgrade the groundwater temperature reaches even $20^{\circ} \mathrm{C}$ (in summer months), i.e. the groundwater temperatures are higher from 3 to $6{ }^{\circ} \mathrm{C}$. Fig 2 .
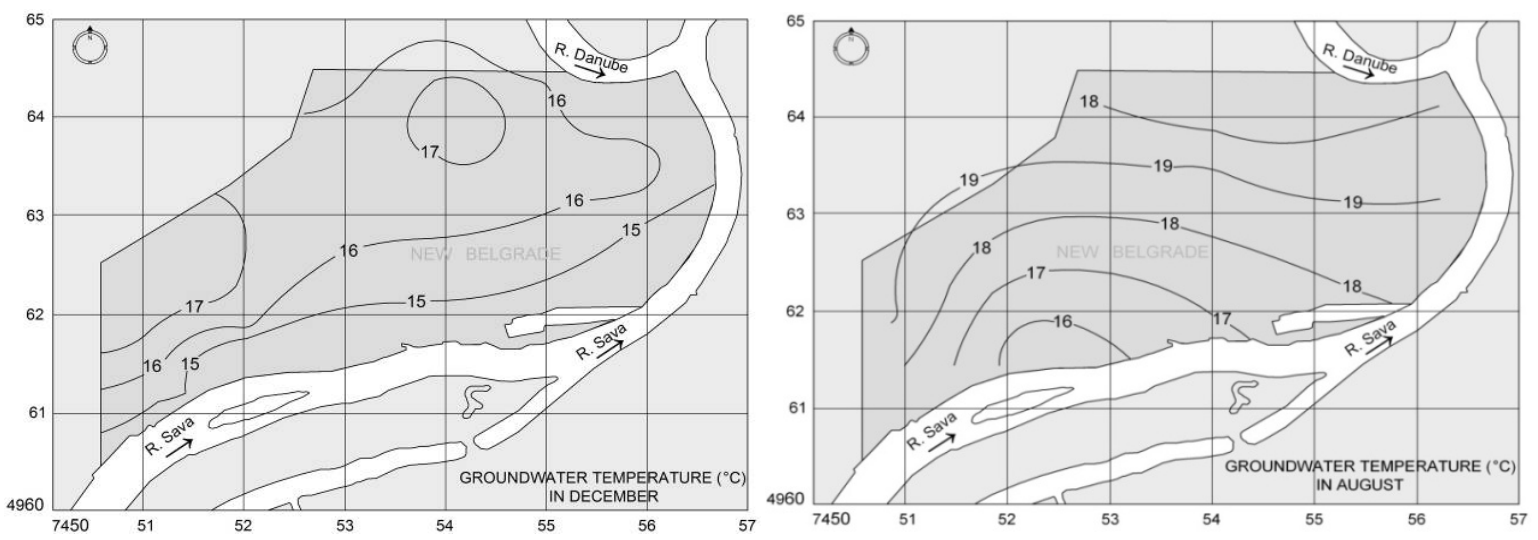

Fig. 2. Hydroisotherm maps of the territory of New Belgrade

The available quantities of groundwater have been observed by regions whose borders correspond with hydrogeological characteristics of the terrain and conditions of groundwater formation. The territory of the Republic of Serbia is divided into eastern part, central and western parts of the territory (Table 1). 
Table 1.

\begin{tabular}{|c|c|c|c|c|c|c|c|c|c|}
\hline & \multicolumn{3}{|c|}{$\begin{array}{l}\text { Estimated quantities } \\
\text { of groundwaters for } \\
\text { all purposes }\left(1 \cdot \mathrm{s}^{-1}\right)\end{array}$} & $\begin{array}{l}\text { Total } \\
\left(1 \cdot \mathrm{s}^{-1}\right)\end{array}$ & $\begin{array}{l}\text { Total } \\
\text { heat } \\
\text { power } \\
\text { (MW) }\end{array}$ & \multicolumn{3}{|c|}{$\begin{array}{c}\text { Available } \\
\text { quantities for } \\
\operatorname{SGTE}\left(1 \cdot \mathrm{s}^{-1}\right)\end{array}$} & $\begin{array}{c}\text { Heat } \\
\text { power } \\
\text { for } \\
\text { SGTE } \\
(\mathrm{MW})\end{array}$ \\
\hline & \multicolumn{3}{|c|}{$\begin{array}{c}\text { Groundwater } \\
\text { temperature }\left({ }^{\circ} \mathrm{C}\right)\end{array}$} & & \multicolumn{4}{|c|}{$\begin{array}{c}\text { Groundwater } \\
\text { temperature }\left({ }^{\circ} \mathrm{C}\right)\end{array}$} & \\
\hline & $10-16$ & $\begin{array}{l}16- \\
22\end{array}$ & $\begin{array}{c}22- \\
30\end{array}$ & & & $10-16$ & $\begin{array}{l}16- \\
22\end{array}$ & $\begin{array}{c}22- \\
30\end{array}$ & \\
\hline & 1 & 2 & 3 & 4 & 5 & 6 & 7 & 8 & 9 \\
\hline \multicolumn{10}{|c|}{ Eastern Serbia } \\
\hline $\begin{array}{l}\text { Alluvial } \\
\text { deposits }\end{array}$ & 15750 & 0 & 0 & 15750 & 388 & 5510 & 0 & 0 & 138 \\
\hline $\begin{array}{c}\text { Neogene } \\
\text { aquifer }\end{array}$ & 2090 & 340 & 200 & 2630 & 73 & 730 & 155 & 105 & 34 \\
\hline Karstic aquifer & 5080 & 130 & 50 & 5260 & 110 & 725 & 48 & 25 & 23 \\
\hline $\begin{array}{c}\text { Fractured } \\
\text { aquifer }\end{array}$ & 200 & 60 & 50 & 310 & 11 & 71 & 28 & 25 & 5 \\
\hline TOTAL & 23120 & 530 & 300 & 23950 & 582 & 7036 & 231 & 155 & 200 \\
\hline \multicolumn{10}{|c|}{ Central and western Serbia (Including Belgrade) } \\
\hline $\begin{array}{l}\text { Alluvial } \\
\text { deposits }\end{array}$ & 29000 & 0 & 0 & 29000 & 728 & 10150 & 0 & 0 & 255 \\
\hline $\begin{array}{c}\text { Neogene } \\
\text { aquifer }\end{array}$ & 4700 & 350 & 320 & 5370 & 159 & 1645 & 150 & 140 & 60 \\
\hline Karstic aquifer & 7000 & 380 & 130 & 7510 & 205 & 2450 & 150 & 45 & 73 \\
\hline $\begin{array}{c}\text { Fractured } \\
\text { aquifer }\end{array}$ & 250 & 90 & 60 & 400 & 15 & 88 & 45 & 30 & 7 \\
\hline TOTAL & 40950 & 820 & 510 & 42280 & 1107 & 14333 & 345 & 215 & 395 \\
\hline \multicolumn{10}{|c|}{ Northern Serbia } \\
\hline $\begin{array}{l}\text { Alluvial } \\
\text { deposits }\end{array}$ & 12100 & 0 & 0 & 12100 & 304 & 4235 & 0 & 0 & 107 \\
\hline $\begin{array}{c}\text { Plioquaternary } \\
\text { deposits }\end{array}$ & 5100 & 200 & 100 & 5400 & 146 & 1785 & 100 & 50 & 54 \\
\hline $\begin{array}{c}\text { Neogene } \\
\text { aquifer }\end{array}$ & 800 & 200 & 100 & 1100 & 38 & 280 & 100 & 50 & 16 \\
\hline Karstic aquifer & 0 & 0 & 0 & 0 & 0 & 0 & 0 & 0 & 0 \\
\hline TOTAL & 18000 & 400 & 200 & 18600 & 617 & 6300 & 200 & 100 & 177 \\
\hline $\begin{array}{c}\text { TOTAL } \\
\text { TERRITORY }\end{array}$ & 82070 & 1750 & 1010 & 84830 & 2306 & 27669 & 776 & 470 & 770 \\
\hline
\end{tabular}

* Groundwater temperature $10-16{ }^{\circ} \mathrm{C}, \Delta \mathrm{T}=6{ }^{\circ} \mathrm{C}$

Groundwater temperature $16-22{ }^{\circ} \mathrm{C}, \Delta \mathrm{T}=12{ }^{\circ} \mathrm{C}$

Groundwater temperature $22-30{ }^{\circ} \mathrm{C}, \Delta \mathrm{T}=18{ }^{\circ} \mathrm{C}$ 


\section{Discussion}

As can be seen from Table 1, the territory of the Republic of Serbia is divided into eastern part to which there belong estimated available quantities for SGTE of about $74001 \cdot \mathrm{s}^{-1}$, namely the available heat power amounts about $200 \mathrm{MW}$, central and western parts of the territory (to which the capital Belgrade also belongs) have about $15000 \mathrm{l} \cdot \mathrm{s}^{-1}$, which is adequate to about $400 \mathrm{MW}$ of heat power, and northern part of the territory with available $6600 \mathrm{l} \cdot \mathrm{s}^{-1}$, namely about $180 \mathrm{MW}$ of heat power. Taking the whole territory of the Republic into account, the total estimated quantities of groundwaters for all purposes amount about $85 \mathrm{~m}^{3} \cdot \mathrm{s}^{-1}$, the total heat power is about $2306 \mathrm{MW}$, the available resources of subgeothermal energy amount about $29 \mathrm{~m}^{3} \cdot \mathrm{s}^{-1}$, namely over $770 \mathrm{MW}$ of heat power (Figure $1 \mathrm{~b}$ ).

If the obtained data are crossed according to types of water bearing structures, it can be seen that intergranular environments in alluvial deposits are far the most abundant. The positionslocations of the biggest towns in Serbia correspond with these environments, thus the possibilities of applications in them are the highest.

If $t$ he temperature of groundwater is observed as a p arameter, it can be seen $t$ hat groundwaters with the temperature range of $10-16^{\circ} \mathrm{C}$ are most widely distributed. Waters of this temperature in the areas of big towns can be affected by the heat island effect being the most convenient ones for the use of heat pumps.

Utilisation has been mostly related to the territory of the city of Belgrade so far occurring individually, not organized. According to recorded users on the territory of Belgrade, for the needs of climatization of buildings, overall $1001 \cdot \mathrm{s}^{-1}$ of groundwater of $12^{\circ} \mathrm{C}$ to $16^{\circ} \mathrm{C}$ has been used, while on the territory of whole Serbia the quantities do not exceed $2501 \cdot \mathrm{s}^{-1}$ (overall about 100 users).

On the basis of the stated data, the great potential of subgeothermal resources in Serbia is obvious. The current energy crisis and increasing costs of fossil fuels used for heating(it is primarily related to natural gas whose price rises every year) impose the necessity to take seriously into account the utilisation of subgeothermal resources instead of ignoring it.

The significance of such a way of heating/cooling (by utilisation of SGTE) in building has been highly recognized in the EU. At the end of the last century the member states of the EU completed projects of rehabilitation of the existing housing in order to save energy tending to consume energy for heating lower than $80-100 \mathrm{kWh} \cdot \mathrm{m}^{-2}$ annually. In Serbia, the state is still significantly different. The existing buildings are one of the highest consumers of energy in the Republic. Almost 50\% of the consumed energy in Serbia is used in buildings, among which $65 \%$ for building heating. Almost the third of overall energy needs of Serbia is related to heating of residential and office buildings. According to estimation, the annual energy consumption for residential heating in Serbia ranges from 150 to $250 \mathrm{kWh} \cdot \mathrm{m}^{-2}$ depending on the age and the state of buildings. The structure of energy consumption is exceptionally unfavourable: $26 \%$ of flats are connected to heating plants; $30 \%$ of households use electrical energy; $20 \%$ of them use firewood; $15 \%$ coal; $<6 \%$ gas.

Consequently, for the lowest level of consumption (heating) the most qualitative energy (electrical energy) is mostly consumed. The aim of the applied measures is to achieve the reduction of energy consumption in office buildings and public facilities of $80-100 \mathrm{kWh} \cdot \mathrm{m}^{-2} /$ annually and in individual houses to $70-90 \mathrm{KWhm}^{2} /$ annually, and in flats for collective dwelling to $65-80 \mathrm{kWh} \cdot \mathrm{m}^{-2} /$ annually. 
Buildings in Serbia are real energy wasters. Over $70 \%$ of existing residential buildings were constructed before passing the first serious regulations on thermal protection in the eighties of the last century. Bearing in mind that, annually, only $1 \%$ of the existing residential buildings is constructed, it is obvious that the basic resource for applications of energy efficiency measures of any sorts are the existing residential buildings. If only urban area is rehabilitated, i.e. 1.6 million of flats, in the period of the following ten years, that is the work worth 4.5 milliard $€$ or 450 million $€$ annually. Such a wide action would result in the fast creation of conditions for the application of SGTE for due to considerably reduced needs for energy far larger number of facilities could use these resources.

Accordingly, there also goes the comparative analysis of expenses required for the production of $1 \mathrm{MWh}$ of heat energy in relation to the kind of the energy resource, the price of the energy resource, and the manufacturing price in the Republic of Serbia in the season 2010/2011 indicating the highest cost-efficiency of the subgeothermal energy utilisation (Table 2). The analysis has been carried out in relation to the following parameters: natural gas is imported from Russia, the kind of coal is lignite, the approximate price of a pellet is $140 € / \mathrm{t}$, hydrogeothermal energy is from heat pumps with the approximate COP 1:4, and the price of electrical energy of $0.05 € / \mathrm{KWh}$.

Table 2. Comparative analysis of expenses required for production of $1 \mathrm{MWh}$ of heat energy in relation to kind of energy resource, price of energy resource, and manufacturing price in Republic of Serbia in December 2010

\begin{tabular}{ccc}
\hline Kind of energy resource & $\begin{array}{c}\text { In relation to energy } \\
\text { resource price }(€)\end{array}$ & Manufacturing price $(€)$ \\
\hline Natural gas & 52 & 72 \\
Mazut & 48 & 68 \\
Coal & 32 & 52 \\
Pellet & 38 & 58 \\
Hydrogeothermal energy (SGTE) & 15 & 35 \\
\hline
\end{tabular}

Nowadays, in Serbia, about 50-55\% of overall energy consumption is used in building and about $70 \%$ out of that for heating and cooling. By correct investment, with energy savings, energy consumption could be even halved, with invested money refund in the period of five years. The first step is the reduction of loss with final consumers -in flats. The energy rehabilitation of an average flat in Serbia with the surface of $70 \mathrm{~m}^{2}$ requires about 3000-4000 $€$. By such investment from 100 to $150 \mathrm{kWh} \cdot \mathrm{m}^{-1}$ would be saved annually, meaning 400-600 $€$ annually at nowadays' prices. In this way such investment is repayed in the period of four to seven years.

In order to establish economic justifiability of the SGTE system in new buildings it should be compared to conventional heating systems with regard to initial investment, maintenance expenses, system duration, and cost price of heating resources. Experiences indicate that initial investment in subgeothermal systems (capable to deliver $1 \mathrm{KW}$ of thermal power) ranges within the scope of $850 €$ per $\mathrm{kWh}$ for heating, and up to $1000 €$ per $\mathrm{kWh}$ for combined heating and cooling systems. The initial investment prices in conventional systems are generally lower to some extent than in hydrogeothermal ones being about $40 \%$ in heating systems, namely $20 \%$ in combined cooling and heating systems. It should be stated that in recent years the prices of STGE systems have dropped significantly approaching those of conventional ones. Unlike the initial investment, the maintenance prices are lower in hydrogeothermal systems, about $50 \%$ in combined cooling and heating systems. The use of STGE in Serbia is not charged, once obtained licence for groundwater exploitation is renewed 
every five years. Taking into account significant raising of prices of all kinds of fossil fuels, the economic cost-efficiency of this kind of heating is obvious.

Besides, we should bear in mind the reduction of $\mathrm{CO}_{2}$ emission into atmosphere. As Serbia has signed the Kyoto Protocol, via the system of "quota trade" compensation financial means are obtained on behalf of "preserved" thousand tonnes of $\mathrm{CO}_{2}$ emission into atmosphere. The current Law on E nergetics introduces categories of privileged users, namely legal persons using renewable energy resources anticipating a set of benefits and facilities for them (tax free import of heat pumps, etc.).

\section{References}

[1] Milenic, D., Vasiljevic, P., Vranjes, A.: Criteria for use of groundwater as renewable energy source in geothermal heat pump systems for building heating/cooling purposes, Elsevier, Energy and Buildings, 2010, pp. 649-657

[2] Milenic, D., Vranjes, A., Savic, N., Veljkovic, Z.: Indicators of impact of heat island effect on ground water energetic potential on the territory of New Belgrade, Serbia, Europe, Proceedings of the XXXVI IAH Congress, Toyama, Japan,2008

[3] Milenic, D., et al: Exploration and application of renewable subgeothermal groundwater resources in the concept of energy efficiency increase in building, Project Number 33053, Strategic project for technological development for R.Serbia, 2011-2014 (in Serbian)

[4] Stevanovic, Z., Milenic, D., Dokmanovic, P., Martinovic, M., Saljnikov, A., Komatina, M., Antonijevic, D., Vranjes, A., Magazinovic,S.,: Optimization of energy utilization of subgeothermal water resources, Project Number 18008, S trategic project for technological development for R.Serbia, 2008-2010 (in Serbian)

[5] Vranjes, A., 2008: Hydrogeothermal resources of the city of Belgrade territory, phD project, University of Belgrade, Faculty of Mining and Geology

[6] Water management basics of Serbia, 2000 